\title{
Selecting an Appropriate Publication Outlet: A Comprehensive Model of Journal Selection Criteria for Researchers in a Broad Range of Academic Disciplines
}

\author{
Linda V. Knight and Theresa A. Steinbach \\ DePaul University, Chicago, Illinois, USA
}

lknight@cdm.depaul.edu; tsteinbach@cdm.depaul.edu

\begin{abstract}
Building upon previously published articles from 18 different disciplines, this research delves into the area of how academics inform one another, addressing the issue of how academic scholars can determine the optimum journal for submission of their research. A comprehensive model of the journal selection process is developed, including 39 detailed considerations spread over three major categories: likelihood of timely acceptance; potential impact of the manuscript (journal credibility, prestige, visibility); and philosophical and ethical issues. Specific guidelines are given for evaluating such concepts as manuscript-journal "fit," journal prestige, and journal visibility. The graphical model developed here assists authors in comparing journal alternatives and provides new researchers with insights into how the three primary journal selection categories are weighed and balanced. In addition, less commonly understood concepts, such as Time to Publication, Review Cycle Time Delay, and Publication Time Delay, are identified and named, and their relationships are defined in this article. On a broader level, this research demonstrates that scholars across disciplines have substantial common interests with respect to journal publishing, that the ties that unite academics seeking to publish are strong, and that the potential for future crossdisciplinary research in the area of how academics inform one another is correspondingly robust.
\end{abstract}

Keywords: Journal, research, outlet, journal selection, journal publication, journal submission, publishing, manuscript.

\section{Background}

The goal of this research was to develop a comprehensive model of the considerations that an author ought to contemplate when selecting a journal for submission of a manuscript. Most academics are required to conduct research and publish results. Journal selection is particularly important to academics because as Donovan (n.d.) explained:

Material published as part of this publication, either on-line or in print, is copyrighted by the Informing Science Institute. Permission to make digital or paper copy of part or all of these works for personal or classroom use is granted without fee provided that the copies are not made or distributed for profit or commercial advantage AND that copies 1) bear this notice in full and 2) give the full citation on the first page. It is permissible to abstract these works so long as credit is given. To copy in all other cases or to republish or to post on a server or to redistribute to lists requires specific permission and payment of a fee. Contact 0HPublisher@InformingScience.org to request redistribution permission.
Although we all publish in a range of academic forms and forums, such as conference abstracts, book reviews, papers in conference proceedings, invited chapters, and books and monographs..., it is the peer-reviewed journal articles that receive the most notice from promotion panels and search committees... (p. 1) 
Academics typically make journal selection decisions repeatedly throughout their careers. Since the submission and evaluation process can easily take months and academic researchers are expected to submit a manuscript to only one journal at any given time, the proper selection of a journal is critical to publishing success. Yet, we found very little prior research specifically directed at the topic of journal selection and no existing model or framework to guide the process.

Our initial goal was to develop a model of journal selection for the disciplines in which we typically publish, Information Systems and Informing Science. Here Information Systems is defined as "the field of inquiry that attempts to provide the business client with information in a form, format, and schedule that maximizes its effectiveness," while Informing Science is defined as the emerging transdiscipline whose goal is to "provide their clientele with information in a form, format, and schedule that maximizes its effectiveness" (Cohen, 1999). Thus, Information Systems is a subset of Informing Science, and Informing Science overlaps with virtually all other disciplines, since it is difficult to conceive of a discipline that would not include the need to inform efficiently and effectively. Given the breadth of these disciplines, it soon became apparent that any journal selection model that would be appropriate for Information Systems and Informing Science would also be appropriate for a wide range of academic researchers in a variety of fields. Thus, our goal became the development of a comprehensive model that would guide the journal selection process for academic authors in general, regardless of discipline. Initially, we expected this model to include coverage of some disciplinary distinctions; however, as the rest of this paper demonstrates, we ultimately found little differentiation, even between widely disparate disciplines. Table 1 lists the major disciplines researched for this study.

Table 1: Disciplines researched as part of this study

\begin{tabular}{|l|l|l|}
\hline Agriculture & Finance & Journalism \\
\hline Communications & Geography & Library/ Information sciences \\
\hline Computer Science & Healthcare & Nursing \\
\hline Economics & Information Systems & Psychology \\
\hline Education & Information Technology & Sociology \\
\hline Engineering & Informing Science & Women's Studies \\
\hline
\end{tabular}

\section{Previous Research}

Despite searching within a wide range of academic disciplines, we found only two prior research papers directly aimed at the journal selection process. Both appeared in nursing journals. The first, a case study in a nursing journal, detailed the process of submitting an article to six different journals before achieving acceptance (van Teijlingen \& Hundley, 2002). While the authors did not specifically develop a framework or model of the journal selection process, they did highlight insights that they had gained into the process. These include matching the writing style and terminology used within the journal, meshing with the multidisciplinary or unidisciplinary nature of the journal, the journal's lag time to publication, the level of credibility attached to the journal, and the journal's Impact Factor, defined as the number of times an average article in that journal is cited within a year. The second article on the journal selection process (Saver, 2006) advised authors to consider whom they want to reach, whether the journals they are considering are peerreviewed, and how often the journals are published (as an indicator of how long it might take an article to be published).

A related article that does not directly address the journal selection process as a whole, argues that bibliometrics can be used to identify suitable journal outlets (Robinson, 1991). The idea here 
is that "bibliographic coupling occurs when two articles contain citations to the same articles or journals," and that an author could rank potential journal outlets by their citation distance from the author's manuscript. This type of analysis has not been widely adopted, perhaps because it can become cumbersome, and because it does not consider such factors as whether the research has been well enough planned, executed, and described to be accepted by the journal being considered.

\section{Identifying Possibilities}

Before the most appropriate journal can be selected from a list of potential journals, such a list of prospective journals must be developed. Many possibilities exist for the authors to use in building an initial list of potential journals. Authors may begin with journals cited in the reference list of their article (Searing, 2006), assuming that it has been at least sketched out. In other words, in addition to the major outputs of the literature review process (Levy \& Ellis, 2006), authors who are alert to the possibilities also may recognize potential journal outlets for their finished work as a byproduct of their literature review. A Libraries Reference Guide distributed by Washington State University (2007) refers scholars to Ulrich's Periodicals Directory (www.ulrichsweb.com/ulrichsweb/), as well as the Directory of Open Access Journals (www.doaj.org). This same publication recommends Journal Citation Reports (scientific.thomsonreuters.com/products/jcr/), an annual publication that "contains analyzed citation data for individual journal citations," as well as the Journal Info website (jinfo.lub.lu.se/) that summarizes "...reader accessibility, cost data, and a variety of quality metrics for over 18,000 scholarly journals." Cabell's online directory (www.cabells.com/) is recommended by Williams, Hammer, Pierczynski-Ward, \& Henson (2007) who state, "Along with providing a list of article topics, Cabell's explains each journal's guidelines and review process. It also indicates how often a specific journal is cited in other journals." There are also specific guides for specific fields. For example, for nursing, there is CINAHL, the Cumulative Index to Nursing and Allied Health Literature (www.cinahl.com), as well as the Nurse Author and Editor website (www.nurseauthoreditor.com). Many disciplines maintain websites and discussion groups, or journal ranking lists. For Information Systems, there is Lamp's journal ranking site (lamp.infosys.deakin.edu.au/journals/index.php), in addition to the AISNet site (www.aisnet.org), which provides a comparison of a variety of alternative journal rankings. For Informing Science, the Informing Science Institute (www.informingscience.org) is a site to visit. For journalism, Nordicom Finland (www.uta.fi/laitokset/tiedotus/contents/) provides a list of "...central scientific and professional journals in the area of mass media, communication, and journalism. Journals are gathered from all over the world. Most of them are in English. Nordic journals are our speciality." In addition, Northwestern University Library

(www.library.northwestern.edu/collections/journalis m/journalrankings.html) recommends that academics seeking a journalism outlet for their manuscript refer to the Iowa Guide

(fm.iowa.uiowa.edu/fmi/xsl/iowaguide/search.xsl)

\section{Note concerning prior research}

Many of the ideas quoted here from past literature are in fact so axiomatic that many scholars in many disciplines have suggested approximately the same thing. There is no way to say who was first to recommend that a faculty member "Ask your colleagues" or "Consult a librarian," for example. Thus, we have chosen to refer in this research to articles published in a wide variety of fields, choosing articles that seem to us to be particularly insightful, while recognizing that many others likely have stated the same or similar ideas. We are hopeful that readers who are familiar with either a very early suggestion of one of the ideas presented here, or with a particularly well-worded quotation on one of the topics covered here, will forward those references to us for inclusion in future work. 
which Northwestern notes is no longer updated but still useful, Journal Citation Reports, and the Web of Science (scientific.thomsonreuters.com/products/wos/). Finally, beyond these types of resources, colleagues and librarians also may assist a faculty member in identifying a list of journals to consider.

\section{Method}

Prior research from a variety of disciplines was analyzed and organized into categories through the use of a card sorting technique. As a result of this process, five major categories became apparent. These five categories represent the five major considerations that an author should contemplate when selecting a journal for submission of a manuscript: (1) likelihood of acceptance, (2) credibility and prestige of the journal, (3) potential impact of the manuscript (visibility), (4) timeline from submission to publication, and (5) philosophical and ethical issues. Within each category, prior literature was used to compile a list of key considerations when selecting a journal for manuscript submission. Finally, all of these considerations were incorporated into a model of the journal selection process.

\section{Five Major Considerations}

We now discuss each of the five major considerations that an author should contemplate when selecting a journal for manuscript submission.

\section{Likelihood of Manuscript Acceptance}

Perhaps the single most important point in selecting a journal for manuscript submission concerns the "fit" between the journal and the manuscript. As Carroll-Johnson (2001) noted, "Choosing the wrong journal can result in outright rejection or, worse, rejection only after a lengthy peer review process that reveals the paper is just not suitable." The need to avoid rejections and the accompanying time loss raises the issue of how an author can identify a journal that might be a good "fit" for a particular manuscript. The most basic consideration is the fit between the style and length requirements of the journal and the manuscript. Some journals will consider a manuscript that is inconsistent with the journal's style or length requirements, treating these as variables that can be modified before publication. However, some journal editors will reject a nonconforming manuscript outright (Whitney, 1995). Regardless of the journal's position on this issue, there is undoubtedly some benefit in submitting a manuscript that, at least in terms of appearance, fits the expectations of the journal's editor and reviewers. Writing in 1982 on the more generic topic of how to get started publishing, Carroll-Johnson noted:

A careful review of recent issues of various journals will reveal the type of articles typically accepted by each journal. For instance, some journals favor manuscripts with tight research designs and sophisticated statistical analyses while others place less emphasis on rigorous research and more value on practical application for practitioners. (p. 322)

On a similar theme, Brunn (1988) noted, "Whereas some journals may publish long (20-25 page) articles, others publish shorter papers and notes. There are journals that will permit many maps, long tables, extensive bibliographies, and complex statistical analyses; and those that will not." Thompson (1995) recommended that an author:

Read through recent issues to see what the journal's focus seems to be...Most journals publish guidelines for authors either in every issue or periodically. Read them carefully; believe what they say. Some journals also include editorialsread these too if they shed light on editorial policy or style. (p. 342) 
Brunn (1988) observed that successful researchers likely both "study very carefully the contents and editorial statements of journals and discuss the best outlets with colleagues." Mortimer (2001) recommended:

Authors should pay attention to such details as the range and scope of topics published, uses of primary resources, and approaches that contributors take in advancing arguments. These items can indicate the inventiveness of a publication's editor(s) and creative dimensions of the presentations... (p. 181)

In addition to the breadth and depth of coverage, Carroll-Johnson (2001) recommended considering the tone of the journal, whether informal, serious, or scientific. She also suggested attempting to find examples in the target journal of the type of manuscript the author intends to submit.

Klingner, Scanlon, and Pressley (2005) advised that the author in search of a journal to publish a manuscript should "in addition to reading articles, look at the list of editorial board members. If the journal is appropriate, you should know at least some of the editorials by reputation and be at least somewhat familiar with their work." Manuscript-journal "fit" is an even more important consideration for highly selective journals because of the risk of rejection. Klingner et al.(2005) recommended that "if you are considering targeting a journal with a very high rejection rate, you should read a few articles in the journal with an eye to answering the question, 'Is my article as well-reasoned and does it make as great a contribution as the articles this journal publishes?'” While some papers are rejected because of the quality of the underlying research or the quality of the presentation, Donovan (n.d.) noted that some papers also are rejected by journals simply because, while they may fit the overall theme of the journal, they do not fit its specific niche. Further, Donovan observed that this niche changes over time as new editors become associated with the journal. Mortimer (2001) noted, "Potential published authors should not consider the perusal of journals to be a one-time activity...Journals are as fluid and dynamic as are the fields they represent." Mortimer explained the particular importance of becoming aware of changes in a journal's editors and editorial boards. Each journal editor has a unique concept of an ideal article. For example, one editor (Sillars, 2004) described the ideal article as one that involves "core concerns," is "of interest to a wide audience of scholars," is "written in a style that is accessible to a varied academic audience," is "theoretically and socially significant," and is an "ambitious undertaking, with 'ambitiousness' defined in terms of rich, extensive data sets and / or careful and intensive analysis." While a manuscript that addresses core concerns, provides significant new knowledge, and is supported by thorough research would be of interest to most editors, some of the other manuscript characteristics that Sillars lists are less universal. For example, while Sillars does not consider a uni-disciplinary manuscript that is of interest to a narrow niche of scholars as ideal, other editors might. Thus, it is worthwhile for authors to read and thoroughly analyze editorial comments as they apply to the manuscript at hand.

Journals have been accused of a wide variety of publication biases, and these biases, when present, can destroy an otherwise ideal journal-manuscript fit. Donovan (n.d.) opined that rejection sometimes results from what he calls "...geographic prejudice. Most of the leading international journals in any field are published in North America or Europe, have mainly North American or European editors and reviewers, and publish a lot of papers on North America and Europe." Van Teilingen and Hundley (2002) reported, "Publication bias may occur because of a tendency for journals to accept only papers that have statistically significant results and not to report nonsignificant effects...." They also reported that just as significant results are more likely to be reported than those that are not, studies are more likely to be published than articles dealing with methodological issues, and primary research is more likely to be published than secondary analysis or manuscripts dealing with theoretical thinking. Quoting studies by Mahoney in 1977 and Peters and Ceci in 1982, van Teilingen and Hundley (2002) noted that articles from more 'respected' institutions are more readily accepted by journals. Thus, an author considering a journal 
should evaluate recently published articles in terms of authors' geographic spread, emphasis upon reporting only primary studies or only significant results, and prestige level of institutions represented. If there is not a good fit in one or more of these areas, it does not mean that the author should automatically stop consideration of the journal, but it does mean that the author should proceed cautiously, and take particular note of the other aspects of fit discussed in this manuscript. In calling for authors to recognize a journal's biases, we are not supporting or even accepting the existence of the bias. In fact, we applaud authors who refuse to submit to certain publication outlets on ethical grounds. We are, however, recognizing that in matters of journal placement, an author should be practical. Recognizing the existence of a bias allows the author to either eliminate the journal from consideration or devise ways to adapt the article to overcome the bias.

Some researchers believe that you need to select a particular journal before you begin writing, in order to specifically aim your writing. Thompson (1995) explains:

Spend some time before you write picking your target journals for a given project. Rank order two or three as the outlets you select. You need to try to write for specific journals. Editors and reviewers look very carefully at the fit between a manuscript and their publication. (p. 342)

Harper (2006) agrees, noting, "Before writing the manuscript, the author (or authors) should have a journal in mind for submission. This is important for the author in determining what guidelines and writing style to follow." If an author does indeed select the journal before writing, then the advice of Carroll-Johnson (2001) is particularly relevant: "Just prior to sending the manuscript to the editor, reconfirm that you have chosen the right journal..."

There are at least three ways to address a manuscript-journal fit problem. First, Harper (2006) recommends, "In writing the review of the literature, the author should be careful not to overlook citing publications from the journal of choice or publications by authors on the journal's editorial board who are scholarly authorities on the manuscript's topic of focus." Thus, the fit of the article can be enhanced during the writing process. Second, if a high quality journal is a reach for a particular article; its chances of acceptance are enhanced if it is submitted for a special themed issue. Williams et al. (2007) quote a 1995 study by Henson and Buttery that concluded that "often three or four times as many manuscripts are received for general issues as are received for publication in a themed issue." Third, when unsure of the fit between a journal and a manuscript, some authors write the journal's editor for advice. A query letter that includes a description of the topic and why it is important to the journal's readers, as well as a description of the paper itself, is recommended by Saver (2006). However, the overall opinion of those editors who have addressed this topic is that, for an author who does his or her homework and researches the fit between a manuscript and the journal in question, writing the editor in advance of submission is not of significant value. "Most editors would probably encourage the submission unless the content was not the focus of the journal" (Brunn, 1988). Thompson (1995) agrees that query letters prior to submission are generally a waste of time, noting, "The editor will always encourage submission if the manuscript is remotely a possible fit, so as not to miss any prize-winning manuscripts." We would add that, while editors are more likely than not to encourage submission if the topic and methodology are appropriate for the journal, there is still some significant potential benefit in asking an editor's opinion before submitting an article. Some editors will respond, not only with encouragement to submit, but also with specific suggestions on how to strengthen the manuscript to increase its likelihood of acceptance. Editors may call attention to particular aspects of the journal's requirements that are used as a litmus test to weed out articles, or they may make helpful suggestions about how to frame your background literature or the way in which to present your statistical results, for example. Even editors who discourage submission may respond with suggestions of other journals where the manuscript might find a more welcome reception. The key in 
asking an editor's opinion on submission is to write a tightly worded email that accurately describes your research question, your methodology, and the significance of your findings; send it at a slow time for academics; and then read beyond the "yes / no" response to gain insights that will help you improve your likelihood of paper acceptance, whether with this journal or with another.

\section{Journal Reputation}

Journal prestige is an important consideration for an author, since the prestige of the journals in which the author's work is published directly influences the author's evaluation as a faculty member. Robey, Walstrom, Adams, and Swanson (1998), leading a panel on the use of journal ranking or rating lists within some academic departments to evaluate faculty, noted that "publications in a leading journal weigh more heavily in the evaluation of faculty performance." According to Klingner et al. (2005):

You want your work to appear in the best outlet that will accept it. Rewards of all sorts follow from publication in frequently cited, visible journals. These range from more positive personnel reviews, to more favorable grant reviews, to invitations to publish more. (p. 15)

In order to discuss a journal's level of credibility or prestige, we must first consider the definition of these terms. Suber (2002) notes that "if quality is real excellence, then prestige is reputed excellence." Thus, prestige and credibility are based in perception. That perception, while it may not be completely accurate, likely has some basis in fact. As Hutchison, Lee, and White (2004) noted, "Resources and relationships lead to reputations." What then are the key resources and relationships that determine a journal's reputation? Three prior articles, shown in Table 2, lend insight into this question.

Table 2: What makes a journal more prestigious? Factors that raise a journal's reputation

\begin{tabular}{|c|c|c|c|}
\hline & Brorsen (1987) & Klinger (2005) & Robey et al. (1998) \\
\hline 1 & Older & & \\
\hline 2 & Larger circulation & Wider circulation & \\
\hline 3 & Lower acceptance rate & Lower acceptance rate & $\begin{array}{l}\text { Review process, including } \\
\text { lower acceptance rate }\end{array}$ \\
\hline 4 & Less specialized & & \\
\hline 5 & Technical or theoretical & & \\
\hline 6 & & $\begin{array}{l}\text { Well-known editor and edi- } \\
\text { torial board members }\end{array}$ & $\begin{array}{l}\text { Institutional affiliations of } \\
\text { editor and board members }\end{array}$ \\
\hline 7 & & Often quoted over time & \\
\hline 8 & & $\begin{array}{l}\text { High impact factor (often } \\
\text { quoted recently) }\end{array}$ & \\
\hline 9 & & $\begin{array}{l}\text { High visibility in multiple } \\
\text { computerized databases }\end{array}$ & \\
\hline 10 & & & $\begin{array}{l}\text { Affiliation with a prestigious } \\
\text { organization }\end{array}$ \\
\hline 11 & & & $\begin{array}{l}\text { Higher rating in articles that } \\
\text { compare different journals }\end{array}$ \\
\hline
\end{tabular}

As Table 2 demonstrates, we have identified eleven factors cited in the literature that contribute toward raising a journal's reputation, and thus determining its credibility and prestige. Despite a 
willingness to discuss the concept of a prestige journal, authors in a wide variety of disciplines concur that a prestigious journal does not always publish prestigious articles. For example, we find this from an article published in a finance journal, "Editors of some journals recognize and publish influential articles consisting of original research; they also include other types of articles" (Borokhovich, Bricker, \& Simkins, 2000), and this from an article published in an Organization Science journal, "Although higher-prestige journals publish more high-value articles, editorial selection involves considerable randomness" (Starbuck, 2005). Further, Katterattanakul, Han, and Hall (2003) found that in computing fields, "on average, journals with a technical or a specialty focus attain high rankings." This is consistent with Brorsen's (1987) suggestion (noted in Table 2) that technical or theoretical journals tend to be more prestigious, as well as Borokhovich, Bricker, \& Simkins' finding (2000) that "some areas of finance, such as those in corporate finance, tend to appear in journals with higher impact factors than do other articles..." Thus, it appears that many different disciplines have unique subsets that are considered the most prestigious and that journals dedicated to or centering on these subsets tend to be regarded as more prestigious by those in the field.

One way for authors to evaluate the prestige of a journal would be to step through Table 2 and evaluate the journal on each of the eleven criteria listed. However, there are other approaches. An author might ask colleagues for their opinions of the journal. Or, an author might rely on published articles that rank journals using various methods, such as number of citations or opinions of those in the field. Alternatively, an author might rely on a ranked list of journals kept by his or her academic department. While some universities and departments strongly support the use of journal rankings, the very practice of departmental ranking of journals has been criticized on multiple grounds, including the risk of considering local rather than global values and the likelihood of putting the emphasis on the journal's reputation, rather than upon the quality of the faculty member's research (Burt Swanson of UCLA, quoted in Robey et al., 1998). Swanson also opined that "the existence of a list of target journals does not reflect well upon the university...," and that "progress in a field is reflected by its most influential published articles, regardless of where they are published, rather than by the contents of the journals appearing on any particular target list." On the topic of ranking lists, Lang (2003), writing in an Informing Science journal, cited specific examples of journals (including the European Journal of Information Systems, the MIS Quarterly, and Information Systems Research) viewed differently on the two sides of the Atlantic Ocean. In his view:

The prevalent use of journal ranking lists as a basis for tenure and promotion decisions is potentially very damaging. Indeed, some of the findings of international journal ranking studies are hard to believe and it is clear that in many cases they are heavily biased by regional identities and cultural value. (p. 24)

Just as there is considerable debate over the appropriateness of departmental or university journal lists, there is also considerable debate over the use of journal impact factors. The impact factor, which is itself calculated and published by a for-profit academic publisher, the Thompson Corporation, is a recent ratio between the number of citations and the number of articles published by the journal. Impact factor alone, however, is likely too restrictive a measure of journal quality. Peffers and Ya (2003) opined that the best measuring stick for journals is an overall concept of value:

We think that "value" is a broader concept and perhaps more relevant to an applied field of research like IS than other measures, such as quality, rigor, relevance or status. IS researchers have a variety of audiences and purposes in mind when publishing research. Aggregate value is a concept that allows us to summarize the benefit that comes from publication. It is implicit in this measure that 
value can be affected by a journal's quality, novelty, audience size, and audience profile. (p. 79)

Regardless of how authors view elements like journal ranking lists or impact factors, authors desiring to make an optimal journal submission decision must recognize the existence of these elements and their potential impact upon the recognition that a manuscript published in a particular journal is likely to receive.

In addition to journal prestige, quality, or value, authors also need to consider whether to aim for journals situated squarely in their own discipline or to target journals in neighboring or related fields. Referring to a 1982 article by Broder and Ziemer that studied salaries of agricultural economists, Brorsen (1987) noted that the article found that "there is a bonus for publishing within one's own discipline and that people think highly of journals that are familiar to them." On the other hand, some fields are inherently multi-disciplinary in nature and may be more welcoming to high quality journal articles from a variety of fields. An example of such a field is Information Systems (Robey et al., 1998). Recommending academics in other areas consider journals from a broad range of fields, Pollard (2005) explains his viewpoint this way:

For example, my field of study happens to be deaf individuals. However, I do not restrict my publication outlets to the few "deaf journals" that exist. There are many times when something I've written could be of interest to a wider or altogether different audience, even though the content of the article happens to be about deaf people. I can always inform my colleagues in the small deafness field to an article that I have published elsewhere. Informing and motivating a broader audience to find something that I have published in an obscure deaf journal is a lot more difficult. (p. 4)

Balancing the possibility of publication in a prestige journal against the potential time lost in the review process that precedes a rejection is a difficult problem. While Witt (2003) noted that "I will initially send my manuscript to the most prestigious journal," other authors (noted earlier) have put more emphasis upon seeking a journal-manuscript "fit" in order to avoid wasting time with lengthy rejections. The consensus appears to lie with the latter opinion, however, Klingner et al. (2005) point out that "even if your manuscript is not accepted, one reason to favor the best journals is that they tend to provide feedback of the highest quality, which can be quite helpful to you as you work to improve your manuscript."

Ultimately, all authors must face the choice of whether to attempt publication in high quality journals. Thompson (1995) noted:

These are personal decisions. Some people only want to publish in the most respected journals. Some people think the quality of the piece overrides issues involving the quality of the journal; these folks believe that an important article will be recognized no matter what journal publishes the work. (p. 343)

Whether quality articles published in minor journals are appropriately recognized today is a topic for debate. However, projecting into the future, Witt (2003) foresees that "once all journals are electronic and all are indexed in the most popular search engines, where something is published may have far less impact than who actually reads a published article."

\section{Journal Visibility and Potential Article Impact}

Thompson (1995) defined a journal's visibility as "including subscription base and whether the regular readership is homogeneous and includes the people you want to impact." However, in recent years, the Internet has shifted the spotlight away from subscribers and toward a broader 
concept that considers how many people have access both to the article and to its abstract through various online indexes. Witt (2003) noted:

To me, the most important factor impacting publication preferences are beliefs about who has access to and reads each journal. How available is each journal in each country? If I am trying to achieve wide distribution of my thoughts and ideas, I want my manuscript to be in a journal that has the chance of reaching the widest possible readership. Thus, my manuscript submission decisions are based on who will be able to read the published piece: how available is each journal in Canada, the United States, and elsewhere; and what journal databases abstract each journal. (p. 331)

According to a Libraries Reference Guide distributed by Washington State University (2007), "Wide accessibility of a scholarly work allows for, but does not guarantee a correspondingly wide reading audience and as a result can possibly result in a higher number of citations to that work."

Antelman (2004) found that in four disciplines (philosophy, political science, electrical and electronic engineering, and mathematics) freely available articles did have greater research impact, as measured by citations in the ISI Web of Science database. Whether making an article freely available on the Web actually causes greater citations has been debated on several grounds, including the possibility that authors of more important work might be more likely to make it available online (Davis, 2006). In short, a clear causation between freely available Web publication and increased citations has been argued, but not proven. Regardless, a wide potential audience, whether it is facilitated by Internet access to a published article or not, does not necessarily imply that an article will be widely read or cited. The key here is to actually reach a large group that is also the right target audience for an article: those that will read it, rely on and repeat information from it, and cite it in their work (Carroll-Johnson, 2001).

\section{Likelihood of Timely Publication}

Some authors have particularly tight timeframes for publication. Authors with upcoming tenure or promotion cases or who will be seeking a new position by a particular date are most likely to have strict time criteria when selecting a journal outlet for their work. Authors whose data or subject matter is of greatest significance for a limited time have similar strict time criteria. As Lang (2003) observed, "Researchers whose area is topical only within the short or medium-term face the unenviable prospect that the passage of time may render their findings obsolete before they are published." For example, an article about the year 2000 computer problem would have little significance if published now. In addition, authors who hope to influence practitioners may have a particular need for timely publication (Fitzgerald, 2003). In any case, it is axiomatic that all authors have some time criteria, since no academic can reasonably expect to expend unlimited time awaiting publication of an article into which they have already invested considerable time and effort.

Time to journal publication is actually the sum of (1) the time from initial submission to final acceptance of a finished article and (2) the time from final acceptance to actual publication (Searing, 2006). We term these two timeframes the Review Cycle Time Delay and the Publication Time Delay. As shown in Figure 1, the Review Cycle Time Delay can be estimated based on the typical turnaround time for the journal combined with the number of revisions typically required. However, Review Cycle Time Delay also is heavily dependent upon the ability of the author to submit timely updates to the article and the ability of the author to effectively incorporate editorial feedback. When authors ignore or give slight attention to requested editorial changes, the Review Cycle Time Delay extends. Of course, authors are not expected to always directly incorporate every editorial request. However, it is likely that readers will question the same areas as the 
reviewers or editor, so those topics will normally need to be strengthened before a paper is published. When authors rapidly and directly address editorial feedback, they shorten their Review Cycle Time Delay. On the other hand, authors have virtually no control of the Publication Time Delay.

- Journal's Time to Publication $=$ Review Cycle Time Delay + Publication Time Delay

- Journal's Review Cycle Time Delay $=\mathrm{f}(\mathrm{x}, \mathrm{y}, \mathrm{z})$

Where $\mathrm{x}=$ anticipated average review time

$\mathrm{y}=$ anticipated number of review cycles

$\mathrm{z}=$ ability of author to quickly and effectively address editorial feedback

- Journal's Publication Time Delay $=g(p, q)$

Where $\mathrm{p}=$ publisher's processing time once manuscript is complete

$\mathrm{q}=$ backlog of finished articles awaiting publication

Figure 1: Variable Relationships in Determining Time to Publication

Publication Time Delay is actually composed of two elements: the publisher's processing time, along with any publication backlog. Many journals, particularly print journals, have backlogs of a year or more of complete, fully accepted articles awaiting publication. Thus, Publication Time Delay is an area where online journals offer authors genuine advantages. Online journals typically have a much shorter publisher processing time than print journals, and online journals generally have little or no backlog of finalized, accepted articles awaiting publication. Thus, authors with short publication timelines should consider online journals. The advantages and disadvantages of publishing in such journals are discussed in further detail in the following section on philosophical issues.

While authors have little control over Publication Time Delay, journal editors and publishers do have considerable control over its processing time element. Clark, Singleton-Jackson, and Newsom (2000) recommend that journals "adopt timeliness as an important indicator of quality," and that they apply Business Process Redesign (BPR) to the journal publication process. In particular, they recommended that journals use an electronic submission system, a Web-based reviewer form, and a system for tracking papers. Authors seeking timely publication of their work may wish to use these features as one way to identify journals likely to have shorter publication processing time.

For an author attempting to select a journal for article submission, accurately estimating the Review Cycle and Publication Time Delays can be critical. Klingner et al. (2005) recommends that authors "seek information, perhaps by e-mailing the editor, about how long it takes the journal to review an article, how many rounds of review the journal typically requires before it accepts an article, and the publication lag from the point of acceptance." While all editors will be cautious in their response, we would add that authors should be wary of particularly vague responses. For example, all editors should know specifically what their publication backlog is. We also urge authors to keep in mind that their article may well not be "average" for any particular journal. If the journal is a stretch for the article, then even if the article is accepted, its Review Cycle Time Delay is likely to be correspondingly longer.

Some academics, discouraged by long response or publication times from journals, have suggested submitting the same article to more than one journal at a time. However, as Pressman noted (1994), the number of papers accepted by all journals in total would not increase, but by 
increasing the amount of total reviewing in process, journal response times would actually suffer. "...the bottleneck that now lengthens acceptance of a paper will move from the author's list of journals for sequential submission and to the larger pile of papers on the desks of referees and editors because the paper is simultaneously submitted." Pressman also argues that the quality of published articles would suffer since "... a policy of multiple submissions reduces the incentives that a referee has to do a conscientious job and put in the necessary time to thoroughly review each paper." Perhaps for these reasons, combined with tradition, journals expect that submitted manuscripts, not only have not been published elsewhere, but also that they are not currently under consideration elsewhere.

\section{Philosophical and Ethical Issues}

Open Access (OA) journals are journals whose contents are freely available to scholars through the Internet. One list of Open Access journals is available online at www.doaj.org. In their early days, these journals were sometimes criticized on quality grounds, using the argument that anyone can put anything on the Internet. However, Suber (2002) noted:

None of the advantages of traditional scientific journals need be sacrificed to provide free online access to scientific journal articles. Objections that open access to scientific journal literature requires the sacrifice of peer-review, revenue, copyright protection, or other strengths of traditional journals, are based on misunderstandings. (p. 3.1)

Suber further reported, "All the major open-access initiatives agree that peer-review is essential to scientific journals, whether these journals are online or in print, free of charge or 'priced.' Open access removes the barrier of price, not the filter of quality control." Nonetheless, just last year, Searing (2006) cautioned authors to "remember that some tenure committees still look down their noses at upstart electronic-only journals." Even this quotation, however, demonstrates the progress that OA journals have made. Note that authors are cautioned against "electronic-only" OA journals, but not those OA journals that publish in print and also make articles available free of charge online. Many other authors are more enthusiastic about OA journals. For example, Koohang and Harman (2006) refer specifically to "the rise of academic Open Access e-journals."

As OA journals have matured, many have developed impact factors and citation rates equal to similar traditional journals (Koohang \& Harman, 2006). Many also have reputations for peerreview as rigorous as or more rigorous than similar traditional print journals. Further, OA journals are often lauded as providing more rapid dissemination of knowledge, as well as a free and open exchange of information among the broadest possible range of researchers and other interested parties. The alternative to Open Access journals are often journals run by universities or those run by for-profit publishers, whose own agendas may influence journal acceptance or rejection decisions, as well as the way in which papers are edited before they appear to readers. Rather than profit-driven publishing companies, groups. such as the Informing Science Institute (www.informingscience.org), that publish Open Access journals are philosophically committed to making all publications freely available online as well as in print. Not all Open Access journals are equally altruistic, however. Some make research available freely, but charge researchers to publish their materials. At the PLOS Medical Journal, authors pay $\$ 1500$ USD, unless they cannot afford it (Dotinga, 2005). "Biomed Central charges authors or their sponsors a fee for dissemination" (Suber, 2002). Such charges raise the issue of whether at some journals; the key determinant in an article being published might be the author's ability to pay and not the considered opinion of reviewers and editors. Of course, this possibility is no different in the case of print journals. The journal medium does not determine the rigor of the review or the ethics of the editors. 
Some scholars who believe philosophically in the free and open exchange of information have a personal policy that any journal to which they submit their manuscript be Open Access. Others give the advantage to an Open Access journal when all other things are equal, likely because an OA journal virtually guarantees wide availability and, thus, the potential for far greater impact than print. Overall, Park and Qin (2007) demonstrated that scholar opinions of Open Access journals are dependent upon seven factors: perceived journal reputation, perceived topical relevance, perceived availability, perceived career benefit, perceived cost of publishing in the journal, perceived content quality, and perceived ease of use. Interestingly, they found that the more available journals tended to have lower perceived content quality, reflecting the trust issue that continues to plague the Internet. Suber (2002) identified a potential reason for this, noting that since Open Access journals tend to be newer, they are less likely to be considered prestigious than journals that have been publishing for longer periods. As noted previously in Table 2, as early as 1987, Brorsen indicated that older journals tend to be more prestigious. Nonetheless, Suber (2002) noted, "It is only a matter of time before the open access journals have earned prestige roughly in proportion to their quality (or at least have the same disparity between these two that characterizes their well-established traditional counterparts)."

Beyond Open Access, a researcher may have other deeply held philosophical beliefs that play a role in journal selection. Searing (2006), perhaps not coincidentally writing in a library journal, had this advice for authors: "As you consider which journal to submit your work to, ask yourself: Has this publisher dealt fairly with librarians? Is it committed to working on issues that matter to libraries, like long-term access to electronic content? What options will you have to retain intellectual property rights?" Suber (2002) believes copyrights should not be an issue, noting:

...scientists are not profit seekers and their interest lies in dissemination to the widest possible audience. For this purpose, it doesn't matter whether scientists retain copyright of their own articles or transfer the copyright to an open-access journal or repository. Copyright assures authors that authorized copies will not mangle or misattribute their work. And the fact that the holder of the copyright consents to free access sharply separates this kind of open access from what might be called 'Napster for science.' (p. 3.2)

\section{Reorganizing the Categories to Develop a Graphical Model}

Once prior research in all five categories was detailed, it became apparent that the categories could be reorganized into three major divisions:

\section{Likelihood of timely acceptance}

Likelihood of acceptance

Timeline from submission to publication

\section{Potential impact of the article}

Journal reputation (credibility \& prestige)

Journal visibility

\section{Philosophical and ethical concerns}

Open Access

Library issues

Intellectual property / copyright issues 
The first two of these major categories, likelihood of timely acceptance and potential impact of the article, stand alone, while the third, philosophical and ethical concerns, represents overarching considerations that encase the entire journal selection process. Thus, the final graphical model is a two-axis grid, with an outer wrapper of philosophical concerns, as depicted in Figure 2. Each of the quadrants in this model is named for its primary characteristics.

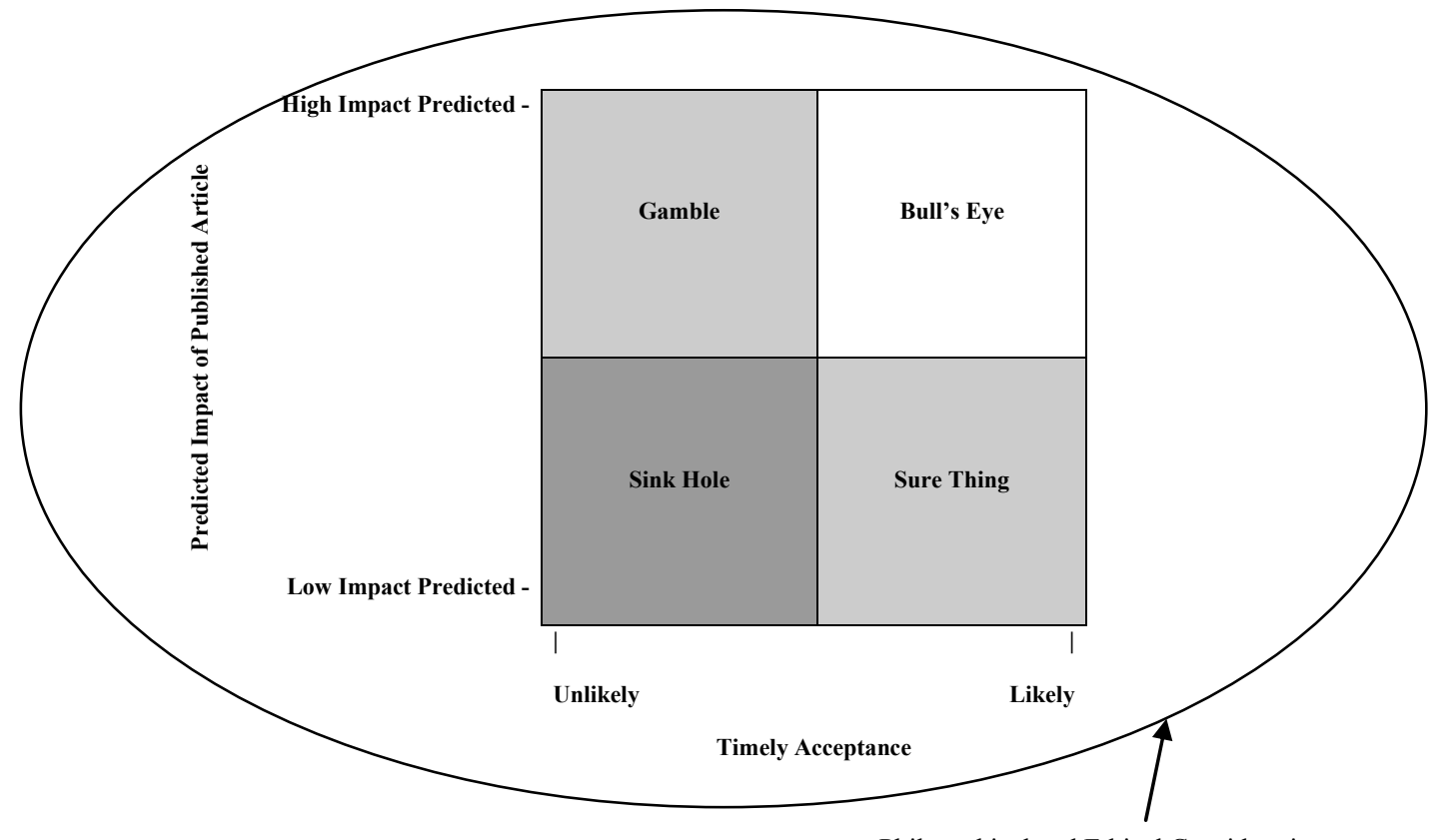

Philosophical and Ethical Considerations

Figure 2: Model of Journal Selection Criteria, Part I, Graphical Model

\section{Assessing and Naming the Quadrants}

\section{Bull's Eye (upper right quadrant)}

The upper right quadrant in Figure 2 is the most desirable since it represents those manuscripts that have a high probability of acceptance at a potentially high impact journal. Typically, the targeted journal has previously published articles on the same topic, the submitted paper uses a similar research methodology, and the disciplinary and audience foci are consistent with the journal's mission and editorial statements. The journal is sufficiently ranked by the author's institution and / or external organizations that the author perceives a positive benefit to both promotion and tenure and long-term career development. The journal's publication process is aligned with the author's time requirement.

\section{Gamble (upper left quadrant)}

If a manuscript evaluates to the upper left quadrant, it is unlikely to be accepted by a high impact journal. Typically, the journal most likely has not published articles of similar topic or in the same discipline, has a bias toward a different form of methodology (quantitative vs. qualitative), or has a very low acceptance rate in general. The manuscript also may not conform to the prescribed style of prose 


\section{Sure Thing (lower right quadrant)}

The lower right quadrant represents those manuscripts that are likely to be accepted but have little or no impact. Typically, the journal is not highly regarded or does not possess even a moderate ranking by either the author's institution and / or external organizations. Often the journal appears to have little benefit to either promotion and tenure or long-term career development. The time from submission to publication has no impact on the topic's relevance.

\section{Sink-hole (lower left quadrant)}

The author should reevaluate the journal choice for their manuscript if upon analysis the plotted point falls into the lower left quadrant. In this case, the manuscript is unlikely to be accepted by a low impact journal. There may be a timeline problem, or the manuscript may be a poor fit for the journal, but in any case, authors need not waste their time submitting to such journals.

\section{Philosophical and Ethical Considerations}

Each author must decide for himself or herself what philosophical or ethical concerns are of significance to them. Regardless of whether these include Open Access, intellectual property, copyright, library, or other issues, these considerations form an umbrella over the entire decision process.

\section{Part II of the Model}

While Part I of the model consists of a graphical representation, Part II of the model lists the factors that authors should consider to determine placement on the graphical grid, as well as the philosophical and ethical concerns represented in its wrapper.

\section{Questions to Assess Likelihood of Timely Acceptance (horizontal axis)}

\section{Topic}

- Has the journal published articles on the same subject as the manuscript?

- If not, has the journal at least published articles on the topics that form the theoretical basis for this research?

- Is the manuscript consistent with the journal's stated mission and editorial statements

\section{Methodology}

- Is the manuscript in harmony with the journal's quantitative or qualitative research bias, if any?

- Has the journal published articles using the manuscript's methodology before?

- If the manuscript reports insignificant results or if it is concerned with methodological issues, has the journal published papers of this same type in the past?

\section{Manuscript}

- Is the manuscript consistent with the disciplinary focus of the journal? Note that if the journal is multidisciplinary, then the manuscript likely should be as well.

- Is the typical time from submission to publication sufficiently short for the author's needs? Consider review lags, revision lags, copyediting lags, and backlogs of manuscripts awaiting publication in the journal.

- How many times is the journal cited in this manuscript? 
- Is the manuscript consistent with the national or international focus of the journal? Note that if the journal is international, then the manuscript likely should be as well.

- Is the manuscript's style of prose consistent with that of the journal?

- Is the length of the manuscript appropriate for the journal? Are the tables, figures, and references consistent with the journal's past publishing?

- Is the manuscript consistent with the journal's instructions for authors?

\section{Journal}

- What is the journal's acceptance rate? If it is low, is the manuscript appropriate for an announced themed issue where acceptance possibilities might be stronger?

- Does the journal regularly publish manuscripts from similarly ranked institutions?

- Does the journal regularly publish manuscripts from the same general part of the world?

\section{Miscellaneous}

- What advice do your colleagues have?

\section{Questions to Assess Predicted Impact of Published Article (vertical axis)}

\section{Journal}

- Is the journal peer-reviewed?

- Are the journal's editorial staff and reviewers academically respected?

- Is the journal ranked or rated by the author's institution?

- Is the journal ranked or rated by a government, a professional association, or a widely recognized research project?

- How often is the journal cited in other journals?

\section{Author}

- What does the author perceive as the potential career benefit from publishing in this journal? Consider how important journal ranking is to the author's university tenure and / or promotion process, as well as how important the author expects this journal's ranking to be to his or her long-range career.

- How long from the time an article is submitted until it is published? If this is a considerable time, consider whether the data or the topic will have less impact if it is not published for a year or two.

\section{Readership / Availability}

- Is the journal regional, national, or international? Consider the journal's leadership team, its editors and reviewers, and its readership.

- What are the readership statistics for the journal?

- Does the journal reach the audience that the author(s) want to target?

- Is the journal read regionally, nationally, or internationally?

- Is the journal available through the Internet or widely available via electronic indexes in university libraries? If not, is the journal available at reasonable cost? 


\section{Questions to Assess Philosophical / Ethical Concerns (ellipse)}

\section{Philosophical and Ethical Issues}

- Is the journal available online and freely accessible to all potential readers?

- Is the journal available only in print form? For a fee?

- If the journal is available only electronically, does the tenure and promotion committee accept the journal as a legitimate publishing forum?

- Is the journal's publisher a university-sponsored or not-for-profit entity, or a for-profit organization?

- Does the journal charge researchers to publish manuscripts?

- Does the author retain copyright of the article?

- Is the copyright transferred to the journal?

- Does the journal deal fairly with all authors?

- Does the journal treat libraries reasonably in terms of its charges?

- Are there any other philosophical or ethical issues of concern to the author?

\section{Discussion}

Applying the model is a multi-step process. First, a scholar must identify a list of potential journals to consider. While this process can vary among disciplines, the earlier section of this paper entitled "Identifying Possibilities" provides researchers with a starting point by describing the major approaches to making a list of journals to consider. Second, using the model's list of philosophical and ethical considerations as a base, the scholar should remove journals from the prospect list that do not meet his or her personal standards. Third, for each journal remaining on the list, the author should carefully consider the model's critical questions with respect to timely acceptance and identify a most likely range on the horizontal axis. The author should also consider the model's critical questions with respect to the published article's likely impact and use that to identify a most likely range on the vertical axis. This identifies a most likely area on the grid for each prospective journal, as shown in Figure 3. At this point, the journals can be visually compared. Clearly inferior choices can be eliminated and remaining choices analyzed and compared. For example, in Figure 3, Journal 4 is clearly inferior to Journal 3, and can be eliminated without further consideration. How to handle the remaining three journals requires deeper consideration. When compared to Journal 3, Journal 2 offers a substantially higher likelihood of timely acceptance, with only slightly lower predicted impact. Similarly, when compared to Journal 1, Journal 2 offers significantly higher impact compared to relatively little loss in likelihood of timely acceptance. Thus, Journal 2 appears to be the superior choice in this example. When choices are close, the author should validate decisions by reviewing the considerations for each axis, as well as his or her own philosophical biases. The model does not spurt out the best journal choice with a mathematical certainty. Rather, the factor list portion of the model provides a comprehensive list of questions for consideration, while the graphical portion of the model provides a visual way to evaluate and compare these considerations.

The model does, of course, have its limitations. Perhaps foremost of these is the fact that researchers often lack the knowledge necessary to precisely answer each question proposed by the model. For some questions, the mere asking of the question may lead a researcher to dig further to discover the data needed. However, in some cases, particularly when evaluating such concepts as the anticipated number of review cycles or a journal's Review Cycle Time Delay, the best answers may be relative comparisons with other journals, rather than absolute figures, and even these can, at times, be difficult. 


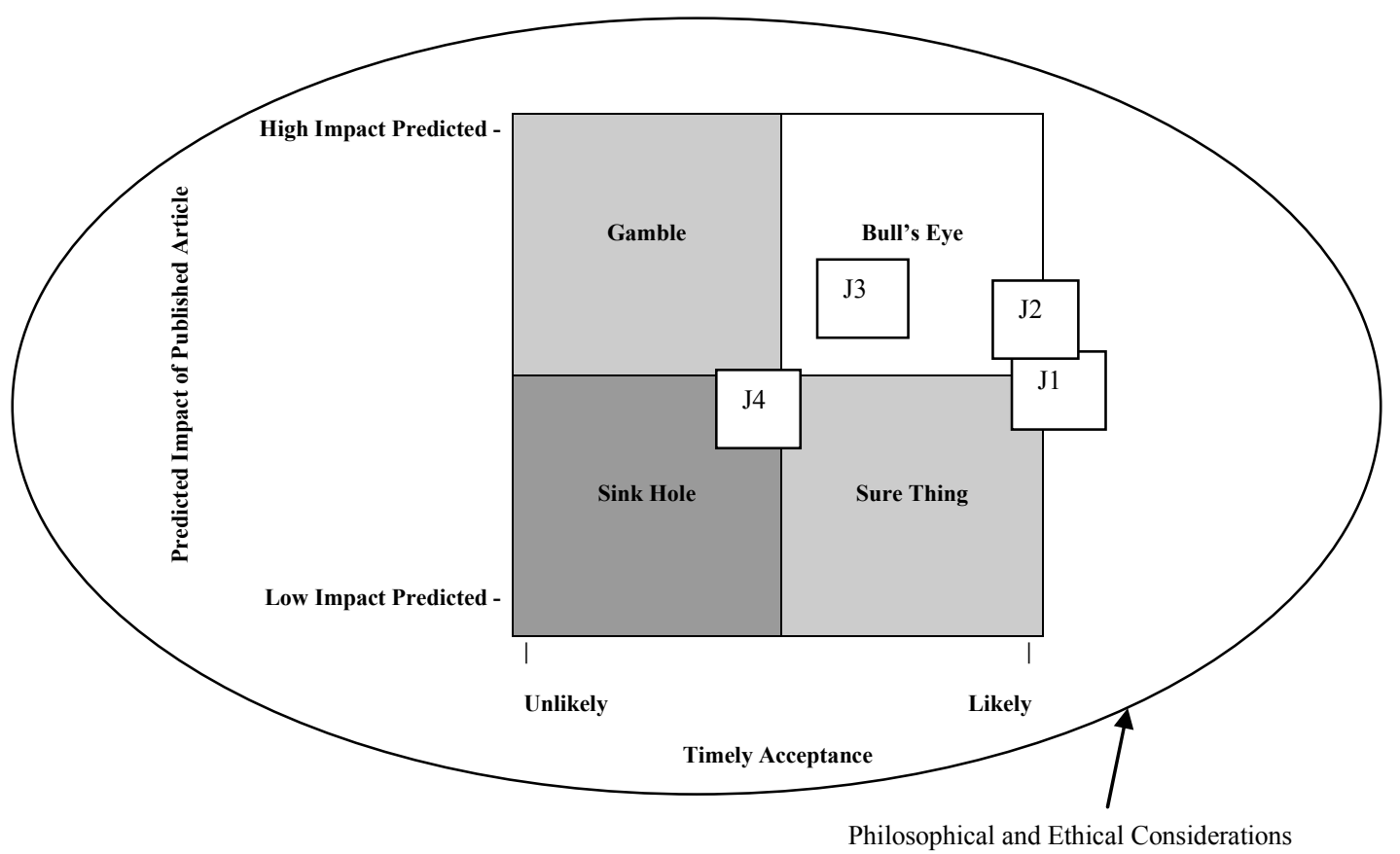

Figure 3: Model Part I, Example showing four possible journals

The ultimate test of any model lies with its application. We believe that this model will be of greatest usefulness in three situations. For new researchers regardless of discipline, the model provides the first single comprehensive list of the multitude of considerations that go into journal selection. In addition, the graphical portion of the model provides these new researchers with insight into how any journal selection decision must balance three major concerns (likelihood of timely acceptance, potential article impact, and philosophical and ethical considerations). While more experienced researchers may already be accustomed to thinking in these terms, they nonetheless can benefit from having a single comprehensive list of decision criteria readily available. Further, experienced researchers considering publishing outside of their home discipline may find the list particularly useful in helping them weed quickly through a plethora of alternative journals.

\section{Conclusion}

The goal of this research was to develop a comprehensive model to guide authors when selecting a journal to which to submit their work. Using the literature from a wide variety of disciplines, we have developed the first comprehensive list of journal selection considerations, and we have analyzed and organized these 39 considerations into three major categories: likelihood of timely acceptance, potential article impact, and philosophical and ethical considerations. Further, we have developed a graphical representation that both assists authors in comparing their journal alternatives and provides new researchers with insights into how the three primary journal selection categories are weighed and balanced. On a broader level, we have established that scholars across disciplines have common considerations with respect to journal publishing, and we have demonstrated that there is value in researching the process of how we, as academics, inform one another.

Through the process of this research, we became familiar with the literature concerning journal publication in a broad scope of disciplines. While initially we expected to find distinctions among the various disciplines, ultimately we were struck, not by differences, but by commonalities. We found that differences, when they exist, tend to exist among the journals within a discipline, not between disciplines. Thus, we conclude that the ties that unite academics seeking to publish are strong, and the potential for future cross-disciplinary research in the area of how we as academics 
inform one another is correspondingly robust. We intend to follow-up this research with an article on the journal review process. More importantly, we hope that this article has inspired other scholars to consider researching further the process of how we, as academics, inform one another.

\section{References}

Antelman, K. (2004). Do open-access articles have a greater research impact? College \& Research Libraries, 65(5), 372-382.

Borokhovich, K. A., Bricker, R. J., \& Simkins, B. J. (2000). An analysis of finance journal impact factors. The Journal of Finance, 55(3), 1457-1469.

Brorsen, B. W. (1987). Observations on the journal publication process. North Central Journal of Agricultural Economics, 9(2), 315-321.

Brunn, S. D. (1988). The manuscript review process and advice to prospective authors. Professional Geographer, 40(1), 8-14.

Carroll-Johnson, R. M. (2001). Submitting a manuscript for review. Clinical Journal of Oncology Nursing, $5(3), 13-16$.

Clark, A., Singleton-Jackson, J., \& Newsom, R. (2000). Journal editing: Managing the peer review process for timely publication of articles. Publishing Research Quarterly, 16(3), 62-71.

Cohen, E. (1999). Reconceptualizing information systems as a field of the transdiscipline informing science: From ugly duckling to swan. Journal of Computing and Information Technology, 7(3), 213-219.

Davis, P. M. (2006). Letter to the editor. College \& Research Libraries, 67(2), 103-104.

Donovan, S. K. (n.d.). The importance of resubmitting rejected papers. Retrieved November 26, 2007, from http://www.ahima.org/perspectives/editorial resources.asp

Dotinga, R. (2005). Open-access journals flourish. Wired. Retrieved November 20, 2007, from http://www.wired.com/print/medtech/health/news/2005/04/67174.

Fitzgerald, B. (2003). Introduction to the special series of papers on informing each other: Bridging the gap between researcher and practitioners. Informing Science: The International Journal of an Emerging Transdiscipline, 6, 13-19. Retrieved from http://inform.nu/Articles/Vol6/v6p013-019.pdf

Harper, F. D. (2006). Writing research reports and scholarly manuscripts for journal publication: Pitfalls and promises. The Journal of Negro Education, 75(3), 322-340.

Hutchison, P. D., Lee, T. M., \& White, C. G. (2004). Development of the journal of information systems from the editors' perspectives. Journal of Information Systems, 18(1), 39-51.

Johnson, N. (1982). Publishing: How to get started. The Personnel and Guidance Journal, 60(5), 321-325.

Katerattanakul, P., Han, B., \& Hong, S. (2003). Objective quality ranking of computing journals. Communications of the ACM, 46(10), 111-114.

Klinger, J. K., Scanlon, D., \& Pressley, M. (2005). How to publish in scholarly journals. Educational Researcher, 34(8), 14-20.

Koohang, A., \& Harman, K. (2006). The academic open access e-journal: Platform and portal. Informing Science: The International Journal of an Emerging Transdiscipline, 9, 71-81. Retrieved from http://inform.nu/Articles/Vol9/v9p071-081Koohang71.pdf

Lang, M. (2003). Communicating academic research findings to IS professionals: An analysis of problems. Informing Science: The International Journal of an Emerging Transdiscipline, 6, 21-29. Retrieved from http://inform.nu/Articles/Vol6/v6p021-029.pdf

Levy, Y., \& Ellis, T. J. (2006). A systems approach to conduct an effective literature review in support of information systems research. Informing Science: The International Journal of an Emerging Transdiscipline, 9, 181-212. Retrieved from http://inform.nu/Articles/Vol9/V9p181-212Levy99.pdf 


\section{Selecting an Appropriate Publication Outlet}

Mortimier, T. (2001). Demystifying publishing: The manuscript submission, external review, and journal production process. Journal of Women's History, 13(1), 181-188.

Park, J-H., \& Qin, J. (2007). Exploring the willingness of scholars to accept open access: A grounded theory approach. Journal of Scholarly Publishing, 38(2), 55-84.

Peffers, K., \& Ya, T. (2003). Identifying and evaluating the universe of outlets for information systems research: ranking the journals. Journal of Information Technology Theory and Application, 5(1), 6384.

Pollard, R. Q. (2005). From dissertation to journal article: A useful method for planning and writing any manuscript. The Internet Journal of Mental Health, 2(2), 1-10.

Pressman, S. (1994). Simultaneous multiple journal submissions: The case against. American Journal of Economics and Sociology, 53(3), 316-333.

Robey, D., Walstrom, K., Adams, D., \& Swanson, B. (1998). Target journals for information systems research: Current practices and controversies. Proceedings of the International Conference on Information Systems, Helsinki, Finland, pp. 420-424.

Robinson, M. D. (1991). Applied bibliometrics: Using citation analysis in the journal submission process. Journal of the American Society for Information Science, 42(4), 308-310.

Saver, C. (2006). Guest series: Writing for publication. Determining what type of article to write. AORN Journal, 84(5), 751-755.

Searing, S. E. (2006). Questions to ask when selecting a journal. In L. J. Hinchliffe \& J. Dorner (Eds.), How to get published in LIS journals: A practical guide (p. 4). Elsevier Library Connect. Retrieved November 26, 2007, from http://libraryconnect.elsevier.com/lcp/0202/LCP0202.pdf

Sillars, A. (2004). New editorial policies and procedures for communication monographs. Communication Monographs, 71(2), 119-120.

Starbuck, W. H. (2005). How much better are the most-prestigious journals? The statistics of academic publication. Organization Science, 16(2), 180-202.

Suber, P. (2002). Open access to the scientific journal literature. Journal of Biology, 1(1), 3.1-3.3.

Thompson, B. (1995). Publishing your research results: Some suggestions and counsel. Journal of Counseling \& Development, 73(3), 342-345.

van Teijlingen, E., \& Hundley, X. (2002). Getting your paper to the right journal. Journal of Advanced Nursing, 37(6), 506-511.

Washington State University Libraries Reference Guide (2007). Retrieved November 26, 2007, from http://www.systems.wsu.edu/bin/libdocs/subject/journalselection.doc

Whitney, C. (1995). CSMC Editor establishes policy. Critical Studies in Mass Communication, 31(12), 5.

Williams, P., Hammer, M., Pierczynski-Ward, M., \& Henson, K. (2007, Spring). The Delta Kappa Gamma Bulletin, pp. 13-20.

Witt, P. A. (2003). Readership is more important than publication outlet. Journal of Leisure Research, 35(3), 331-334. 


\section{Biography}

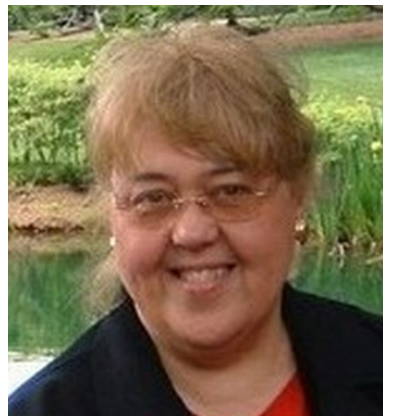

Linda V. Knight, Ph.D., is an Associate Professor, and Director of DePaul University's College of Computing and Digital Media (CDM) Center for the Strategic Application of Emerging Technologies (SAET), a research group that explores leveraging new and emerging technology within organizations. She teaches and conducts research in the area of Information Technology strategy, development, and implementation. In 2006, she was honored to be named a Fellow of the Informing Science Institute. Editor-in-Chief of the Journal of IT Education, she is also Associate Editor of the Information Resources Management Journal, as well as Past President and Fellow of the Society for the Advancement of Information Systems. She serves on MBAA International's Executive Board, this year as President. An entrepreneur and IT consultant, she has held industry positions in IT management and quality assurance management. In addition to a Ph.D. in computer science from DePaul University, she holds a B.A. in mathematics and an MBA, both from Dominican University.

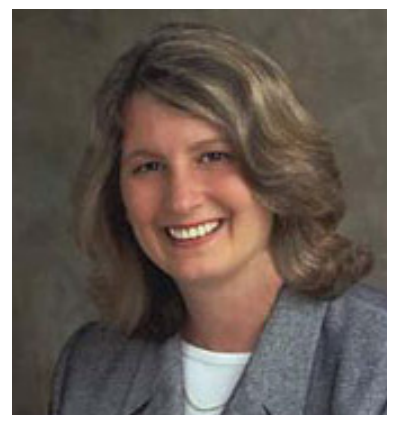

Theresa A. Steinbach, Ph.D., is an Assistant Professor at DePaul University's College of Computing and Digital Media in the School of Computing. Her primary research interests are system development methodology, project management, IT ethics and IT education. She serves on the editorial board of Informing Science: the International Journal of an Emerging Transdiscipline. Prior to teaching full-time, Terry owned her own consulting firm that specialized in maximizing technology for business growth and profits. Her client base included representatives from the banking and nursing home industries, accounting firms, mortgage bankers, park districts and other municipal entities, and small and mid-size retail businesses. In addition to a Ph.D. in Computer Science, she holds a M.S. in Information Systems, an MBA in Quantitative Economics and a B.A. in Mathematics. 